\title{
Microsatellites Cross-Species Amplification across Some African Cichlids
}

\author{
Etienne Bezault, ${ }^{1,2,3}$ Xavier Rognon, ${ }^{2,4}$ Karim Gharbi, ${ }^{2,5}$ \\ Jean-Francois Baroiller, ${ }^{1}$ and Bernard Chevassus ${ }^{2}$ \\ ${ }^{1}$ UMR 110, Cirad-Ifremer INTREPID, 34398 Montpellier, France \\ ${ }^{2}$ INRA, UMR 1313 Génétique Animale et Biologie Intégrative, 78352 Jouy-en-Josas, France \\ ${ }^{3}$ Department of Biology, Reed College, Portland, OR 97202, USA \\ ${ }^{4}$ AgroParisTech, UMR 1313, Génétique Animale et Biologie Intégrative, 75231 Paris, France \\ ${ }^{5}$ Institute of Evolutionary Biology, School of Biological Sciences, University of Edinburgh, Edinburgh EH9 3JT, UK
}

Correspondence should be addressed to Etienne Bezault, ebezault@yahoo.fr

Received 31 January 2012; Accepted 26 March 2012

Academic Editor: Kristina M. Sefc

Copyright ( $) 2012$ Etienne Bezault et al. This is an open access article distributed under the Creative Commons Attribution License, which permits unrestricted use, distribution, and reproduction in any medium, provided the original work is properly cited.

The transfer of the genomic resources developed in the Nile tilapia, Oreochromis niloticus, to other Tilapiines sensu lato and African cichlid would provide new possibilities to study this amazing group from genetics, ecology, evolution, aquaculture, and conservation point of view. We tested the cross-species amplification of 32 O. niloticus microsatellite markers in a panel of 15 species from 5 different African cichlid tribes: Oreochromines (Oreochromis, Sarotherodon), Boreotilapiines (Tilapia), Chromidotilapines, Hemichromines, and Haplochromines. Amplification was successfully observed for 29 markers (91\%), with a frequency of polymorphic $\left(\mathrm{P}_{95}\right)$ loci per species around $70 \%$. The mean number of alleles per locus and species was 3.2 but varied from 3.7 within Oreochromis species to 1.6 within the nontilapia species. The high level of cross-species amplification and polymorphism of the microsatellite markers tested in this study provides powerful tools for a wide range of molecular genetic studies within tilapia species as well as for other African cichlids.

\section{Introduction}

African cichlid fish are of extreme interest for both evolutionary biology and applied genetics purposes, including amazing models for speciation, adaptation, behaviour and neurosciences [1-5] as well as groups of major importance for aquaculture and fisheries (strain selection and improvement, stock assessment, etc.) [6-10]. A wide range of structural and functional genomic resources have been developed for cichlids in the past 15 years, predominantly in the Nile tilapia, Oreochromis niloticus [11-14]. While genome sequencing projects are in progress for several African cichlids, the transfer of genomic resources from $O$. niloticus across the entire group of tilapias sensu lato as well as other African cichlid tribes would provide powerful tools to support a wide range of evolutionary biology studies, including comparative phylogenetics, genome mapping, evolution of gene family sequence and expression, candidate gene analyses for adaptation, and population genetics.

Microsatellite markers are one of the most interesting resources to transfer across lineages, as they can provide numerous locus-specific molecular markers and putatively homologous sequences across taxa. In addition to their high level of polymorphism, the evolutionary conservation of the flanking region of microsatellite loci allows large-scale heterospecific amplification $[15,16]$, as previously shown in various animal groups, particularly fish [17-19]. However, the rate of cross-species amplification varies widely among taxonomic groups and loci $[18,20]$. In addition to their application in population genetics, conserved microsatellite markers are particularly useful for population, species or hybrid identification (especially at early developmental 
stages) and candidate-marker analysis, comparative genetic mapping, and QTL analysis. Furthermore, compared to anonymous multilocus genomic markers (RFLP, AFLP, ISSR) and SNPs, microsatellites present the important advantages of (i) being highly reproducible and very easily transferable between laboratory (with limited equipment and computational requirement), (ii) providing a high polymorphism information contain (PIC) per locus, and (iii) being highly cost efficient when only a small number of loci are needed. For these reasons, microsatellites markers are likely to remain popular for a wide range of ecology and evolutionary studies (e.g., relatedness and parentage analysis, population diversity and demography assessment, noninvasive genetic analysis, and conservation).

Since the first publication of microsatellite markers cloned in O. niloticus [13], thousands have been published and more than 500 have been positioned onto the genetic map of $O$. niloticus and the closely related $O$. aureus $[14,21]$. These microsatellites have been used to map traits of interest, such as sex determination factors $[22,23]$, and have also been found to influence the expression of genes associated to physiological adaptation [24].

Outside the tilapias, microsatellite markers have been developed in a few different Haplochromines species: Copadichromis cyclicos [25], Tropheus moorii [19], Pseudotropheus zebra [26], Astatoreochromis alluaudi [27], Pundamilia pundamilia [28], Metriaclima zebra [29], Pseudocrenilabrus multicolor [30], Paralabidochromis chilotes [31], and Astatotilapia burtoni [32]. However these studies reported a smaller number of markers than that in Nile tilapia. The use of microsatellite markers in Haplochromines has been almost strictly restricted to descriptive population genetics and parentage/relatedness analysis, which represent only a subset of the possibilities offered by having a large set of genomeanchored microsatellite markers, as available for O. niloticus.

Additionally, microsatellites developed outside tilapias were derived exclusively from the most species-rich group of African cichlids and there are very limited genomic resources in all the other "under-studied" African cichlid tribes [3335].

Considering the central position occupied by the Tilapiines sensu lato in the African cichlid phylogeny [38], their large diversity within at least 3 monophyletic clades [39-41], and the important number of species involved in population transfers, hybridisation, and/or invasion $[8,42]$, we decided to investigate the cross-species amplification efficiency of Nile tilapia microsatellites among the different groups of the Tilapiines sensu lato as well as three other African cichlid tribes, to extend the use/availability of this resource across a wide range of African cichlid species, including "understudies" groups. The panel of species investigated then spans a large section of the African cichlid radiation, with an estimated overall divergence time of 33.4-63.7 Myrs [41, 43].

\section{Material and Methods}

Tests of cross-species amplification were conducted in a panel of 15 African cichlid species, representing all three major genera of Tilapiines sensu lato: 7 Oreochromis, 2 Sarotherodon, both genera belonging to the Oreochromines, and 3 Tilapia (Coptodon), belonging to the Boreotilapiines; as well as representatives of 3 other African cichlid tribes, including the derived Haplochromines, and two more basal tribes, the Chromidotilapiines and the Hemichromines (see details in Table 1). Analyses were conducted using 3 to 9 individuals per species (Table 1). Genomic DNA was extracted from fin clips stored in ethanol using a standard phenol-chloroform protocol [44].

The panel of 32 microsatellites was selected from the markers isolated in O. niloticus [13]. Genotyping was obtained by PCR amplification with radioactive $\left(\mathrm{P}^{33}\right)$ labeled primers $[44,45]$. Allele variants were separated on $6 \%$ acrylamide gel electrophoresis. For each marker, the annealing temperature and $\mathrm{MgCl}_{2}$ concentration were adjusted to optimise the efficiency of PCR amplification based on O. niloticus and two others species: one closely related among Oreochromis (O. mossambicus) and one distantly related among the Oreochromines (S. melanotheron). Cross-species amplifications were carried out using these conditions in the 15 studied species (Table 2). For each microsatellite marker, the amplification success has been estimated qualitatively on a 4-level scale based on the quality of the electrophoresis pattern across the test individuals (i.e., "++" for strong and sharp amplification pattern, "+" for good quality pattern with some stutters, echo-alleles or low intensity, "-" for high variance of amplification quality across individuals, very high level of stutter, and/or high frequency of null alleles, and “--" very poor quality pattern, nonspecific or lack of, amplification). For each locus by species combination $(n=480)$, we assessed the amplification success and counted the number of different alleles among individuals. The presence of putative null alleles (i.e., nonamplified alleles) was inferred when a few individuals consistently showed an absence of allele amplification while other individuals from the same species showed high-quality amplification pattern or in the complete absence of heterozygous individuals. Echo-alleles (i.e., supplementary allele coamplifying across individuals producing amplification pattern consistently representing 2 or 4 alleles per individuals, with the longest allele separated from the shortest "cosegregating" allele by an identical length across individuals/alleles) were also identified. Furthermore, the rate of amplification success, the frequency of polymorphic loci $\left(\mathrm{P}_{95}\right)$, and the mean number of allele per locus were calculated per species, genus, and tribe across all studied microsatellites markers.

\section{Results and Discussion}

Very high rates of microsatellite amplification and polymorphism were observed (both 97\%), in the Nile tilapia, with a mean number of alleles per locus of 4.3. Across the 14 other test species, 29 loci gave good quality amplifications (91\%Tables 2 and 3), while 3 markers (9\%) showed a high discrepancy of amplification efficiency and/or unclear amplification pattern (Table 2; see details in supplementary material which 
TABLE 1: Species studied for cross-species amplification tests, with geographic origin, and number of samples analysed per species.

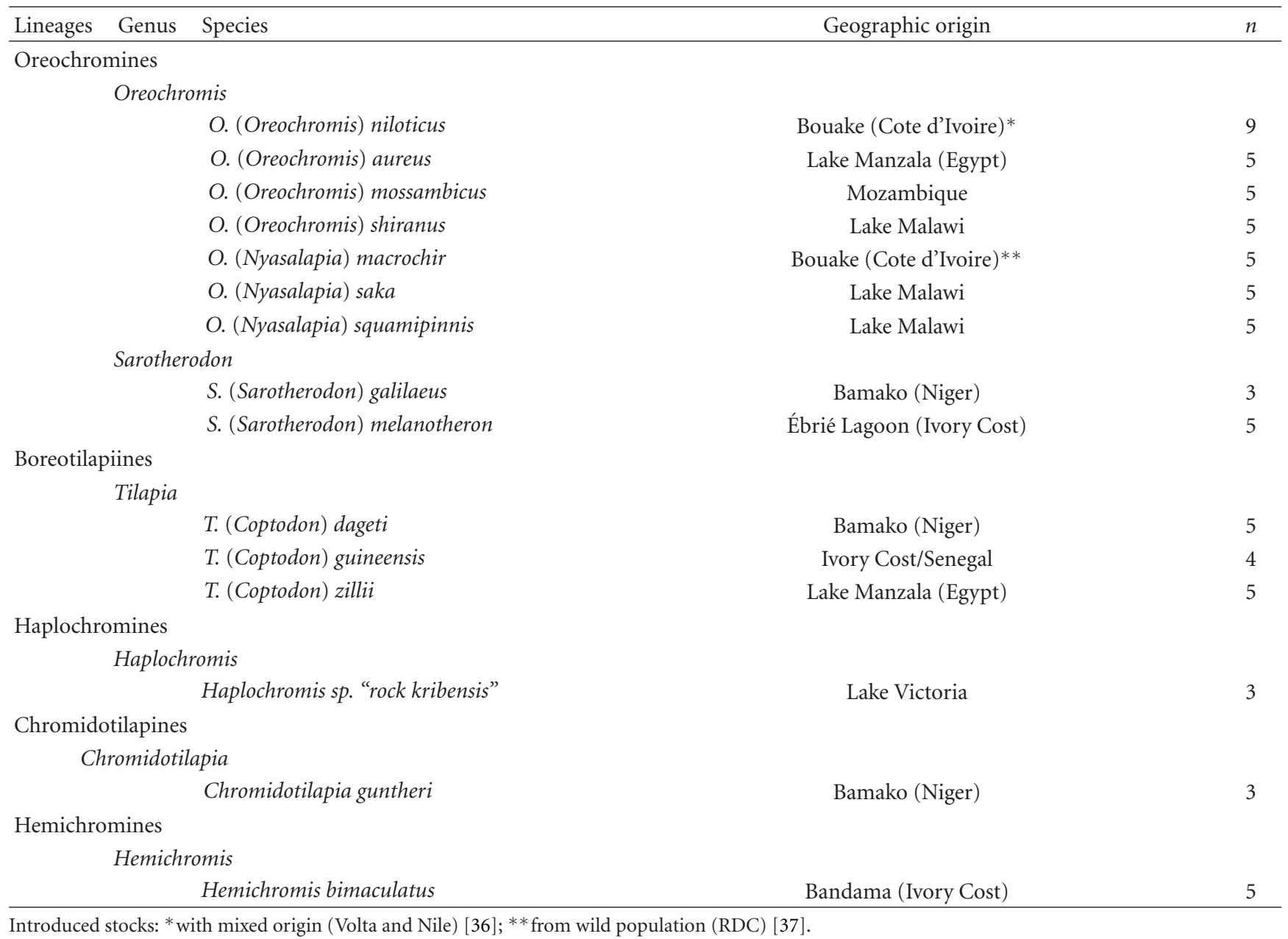

Introduced stocks: ${ }^{*}$ with mixed origin (Volta and Nile) [36]; ${ }^{*}$ from wild population (RDC) [37].

is available online at doi:10.1155/2012/870935: Table S1). Excluding the Nile tilapia, the average intraspecific rate of successful amplification and polymorphism across the panel of 32 markers was more than $70 \%$ (Table 3 ).

The expected relationship between the success of cross-species amplifications and evolutionary distance from marker cloning species $[15,20]$ was observed, reflecting the phylogenetic relationships between the different groups of African cichlids [39-41] (Table 3; see details in supplementary material: Table S2). Within the Tilapiines sensu lato, species from both mouth-brooder genera (i.e., Oreochromis and Sarotherodon), constitutive of the monophyletic clade of the Oreochromines diverged 12.8-21.4 Myrs ago, showed very high and similar amplification (88\% and $86 \%$, resp.) and polymorphism ( $76 \%$ and $85 \%$, resp.) rates, whereas species from the genus Tilapia, belonging to the Boreotilapiines with a divergence time from Oreochromines of 30.6$39.6 \mathrm{Myrs}$, showed lower rates of amplification (67\%) and polymorphism (59\%). The three other African cichlid tribes exhibited lower values for amplification and polymorphism rates: $38 \%$ and $50 \%$, respectively, in the more derived lineage, Haplochromines, whereas a more heterogeneous pattern was found for the two more basal lineages, Chromidotilapiines (i.e., $47 \%$ and $20 \%$, resp.) and Hemichromines (i.e., 19\% and $50 \%$, resp.). Allelic diversity varied with the same trends with a mean number of alleles per locus and species ranging from 3.7 and 3.3, respectively, for Oreochromis spp. and Sarotherodon spp. to 2.4 for Tilapia spp. and 1.6 in average (from 1.4 to 2.3) for the non-Tilapiines groups. The frequency of loci with putative null alleles also appeared to increase in the more distant species (supplementary material: Table S2). Rather than strictly reflecting reductions in polymorphism and/or the loss of the marker loci with increasing phylogenetic distance from the species in which the marker was cloned, these relationships are caused by mutations in the flanking regions complementary to the PCR primers. The conservation of microsatellites loci in the genomes has been shown to be potentially very long, and anyway much longer than the divergence time allowing successful cross-species amplification based on a given pair of primers, generally designed based on the only knowledge of the locus sequence in the species of cloning. The global success of cross-species amplification of a given microsatellite marker and/or the recovery of its different allelic variant (i.e., elimination of null allele) could then be enhanced in target species by either a specific optimisation 
TABle 2: Microsatellite loci tested for cross-species amplification with indications of repeat structure observed in O. niloticus (according to Lee and Kocher, [13]), allele size range of the amplified fragment across all tested species, PCR and electrophoresis conditions (labeled primer, annealing temperature/magnesium concentration ( $\mathrm{mM})$ /electrophoresis Volt-hour), and amplification quality obtained after PCR optimisation tests (from very good ++ to poor --; see detail of the categories in main text); loci presenting a wide cross-species amplification efficiency are in bold.

\begin{tabular}{|c|c|c|c|c|c|}
\hline Loci & GenBank access No. & Structure & Range (bp) & PCR and electrophoresis conditions & Amplification efficiency \\
\hline UNH-008 & $\mathrm{G} 31346$ & Perfect & $196-236$ & $\mathrm{R}^{*} 56 / 1.2 / 6000$ & ++ \\
\hline UNH-102 & G12255 & Perfect & $132-185$ & $\mathrm{R}^{*} 50 / 1.2 / 4500$ & ++ \\
\hline UNH-103 & G12256 & Perfect & $171-260$ & $\mathrm{R}^{*} 48 / 1.2 / 6000$ & + \\
\hline UNH-106 & G12259 & Compound & $115-189$ & $\mathrm{R}^{*} 50 / 1.2 / 3500$ & + \\
\hline UNH-115 & G12268 & Compound & $100-146$ & $\mathrm{~F}^{*} 50 / 1.5 / 3500$ & ++ \\
\hline UNH-117 & G12270 & Interrupted & $108-146$ & $\mathrm{R}^{*} 5411.2 / 4500$ & ++ \\
\hline UNH-120 & G12273 & Compound & - & $\mathrm{R}^{*} 48 / 2 /-$ & -- \\
\hline UNH-123 & G12276 & Perfect & $142-232$ & $\mathrm{~F}^{*} 48 / 1.2 / 4500$ & ++ \\
\hline UNH-124 & G12277 & Perfect & $295-324$ & $\mathrm{~F}^{*} 54 / 1.2 / 7500$ & ++ \\
\hline UNH-125 & G12278 & Compound & $134-198$ & $\mathrm{R}^{*} 48 / 1.5 / 4500$ & + \\
\hline UNH-129 & G12282 & Interrupted & $180-253$ & $\mathrm{R}^{*} 48 / 1.2 / 4500$ & + \\
\hline UNH-130 & G12283 & Perfect & $174-242$ & $\mathrm{R}^{*} 50 / 1.2 / 4500$ & + \\
\hline UNH-131 & G12284 & Perfect & $283-303$ & $\mathrm{~F}^{*} 48 / 2 / 6000$ & - \\
\hline UNH-132 & G12285 & Perfect & $100-134$ & $\mathrm{R}^{*} 52 / 1.2 / 3500$ & + \\
\hline UNH-135 & G12287 & Interrupted & $124-284$ & $\mathrm{R}^{*} 50 / 1.5 / 4500$ & + \\
\hline UNH-138 & G12290 & Perfect & $144-250$ & $\mathrm{R}^{*} 48 / 1.5 / 4500$ & + \\
\hline UNH-142 & G12294 & Interrupted & $142-192$ & $\mathrm{~F}^{*} 48 / 1.2 / 4500$ & ++ \\
\hline UNH-146 & G12298 & Interrupted & $111-149$ & $\mathrm{~F}^{*} 60 / 1 / 3500$ & ++ \\
\hline UNH-149 & G12301 & Perfect & $143-225$ & $\mathrm{R}^{*} 48 / 1.5 / 4500$ & + \\
\hline UNH-154 & G12306 & Perfect & $98-176$ & $\mathrm{R}^{*} 50 / 1.2 / 3500$ & ++ \\
\hline UNH-159 & G12311 & Perfect & $205-267$ & $\mathrm{R}^{*} 55 / 1.2 / 6000$ & ++ \\
\hline UNH-162 & G12314 & Perfect & $125-252$ & $\mathrm{R}^{*} 48 / 1.5 / 6000$ & ++ \\
\hline UNH-169 & G12321 & Interrupted & $124-240$ & $\mathrm{R}^{*} 54 / 1.2 / 3500$ & ++ \\
\hline UNH-173 & G12325 & Perfect & $124-188$ & $\mathrm{~F}^{*} 55 / 1.2 / 4500$ & + \\
\hline UNH-174 & G12326 & Perfect & $146-187$ & $\mathrm{~F}^{*} 48 / 1.5 / 4500$ & ++ \\
\hline UNH-189 & G12341 & Perfect & $135-208$ & $\mathrm{R}^{*} 52 / 1.2 / 4500$ & + \\
\hline UNH-190 & G12342 & Compound & $133-202$ & $\mathrm{R}^{*} 60 / 1 / 4500$ & + \\
\hline UNH-193 & G12386 & Perfect & - & $\mathrm{R}^{*} 48 / 2 / 3500$ & -- \\
\hline UNH-197 & G12348 & Interrupted & $154-228$ & $\mathrm{R}^{*} 50 / 1.2 / 4500$ & + \\
\hline UNH-207 & G12358 & Interrupted & $90-198$ & $\mathrm{R}^{*} 60 / 1.2 / 3500$ & ++ \\
\hline UNH-211 & G12362 & Perfect & 82-194 & $\mathrm{R}^{*} 48 / 1.5 / 3500$ & ++ \\
\hline UNH-216 & G12367 & Perfect & $126-212$ & $\mathrm{R}^{*} 52 / 1.2 / 3500$ & ++ \\
\hline
\end{tabular}

of the amplification conditions or the modification of the sequence of the primers. This is especially appropriate when target species are distantly related to the cloning species of the markers and initial cross-species tests reveal low level of polymorphism with potentially high frequency of null allele (which would heavily bias any allele frequency-based estimates).

To represent the multi-locus pattern of genetic diversity across the 15 study species, we performed a populationbased correspondence analysis using the software Genetix [46]. This multivariate analysis conducted on the genotype matrix allows to represent the clustering pattern among the different species groups, as well as among individuals within each of them in a factorial space (F1, F2, F3). This analysis allowed to clearly resolve the different species, except for
O. saka and O. squamipinnis which are highly overlapping in the factorial space (Figure 1). Three separate groups of species were defined: the Oreochromines species, with all Oreochromis and Sarotherodon species, the Tilapia species, and all non-Tilapiines species. This clustering pattern reflects the phylogenetic relationships between the two tribes of Tilapiines sensu lato, that is, Oreochromines and Boreotilapiines. However the clustering of the three other tribes, which represent the most distant taxa from the source species, reveals the influence of the overall reduced polymorphism in highly distant taxa. This points out the limits of microsatellite size polymorphisms to estimate genetic divergence and/or phylogenetic relationship between too distantly related taxa, due to allele size homoplasy and/or increase of null allele frequency [19]. 
TABLE 3: Results of cross-species amplification performed over the 32 tested microsatellite loci on the 15 African cichlid species studied, including amplification rate, polymorphism rate, and mean number of alleles per locus, estimated per genus and tribe.

\begin{tabular}{|c|c|c|c|c|c|c|}
\hline \multirow{2}{*}{ Groups } & \multirow{2}{*}{$N$ species } & \multirow{2}{*}{ Amplification rate } & \multirow{2}{*}{ Polymorphism $\left(\mathrm{P}_{95}\right)$} & \multicolumn{2}{|c|}{ Mean allele number per locus } & \multirow{2}{*}{$\%$ shared alleles per } \\
\hline & & & & Per group & Per species & \\
\hline O. niloticus & & $97 \%$ & $97 \%$ & - & 4.3 & - \\
\hline Oreochromis spp.* & 6 & $88 \%$ & $76 \%$ & 17.8 & 3.7 & $37 \%$ \\
\hline Sarotherodon spp. & 2 & $86 \%$ & $85 \%$ & 6.4 & 3.3 & $9.2 \%$ \\
\hline Tilapia spp. & 3 & $67 \%$ & $59 \%$ & 6 & 2.4 & $19.7 \%$ \\
\hline Tilapiines* & 11 & $82 \%$ & $74 \%$ & 24.3 & 3.7 & $20.5 \%$ \\
\hline non-Tilapiines & 3 & $34 \%$ & $36 \%$ & 3.4 & 1.6 & $2.3 \%$ \\
\hline Haplochromines & 1 & $38 \%$ & $50 \%$ & - & 1.6 & - \\
\hline Chromidotilapines & 1 & $47 \%$ & $20 \%$ & - & 1.4 & - \\
\hline Hemichromines & 1 & $19 \%$ & $50 \%$ & - & 2.3 & - \\
\hline Total* & & $72 \%$ & $70 \%$ & 25.7 & 3.2 & $5.3 \%$ \\
\hline
\end{tabular}

${ }^{*}$ Excluding O. niloticus.

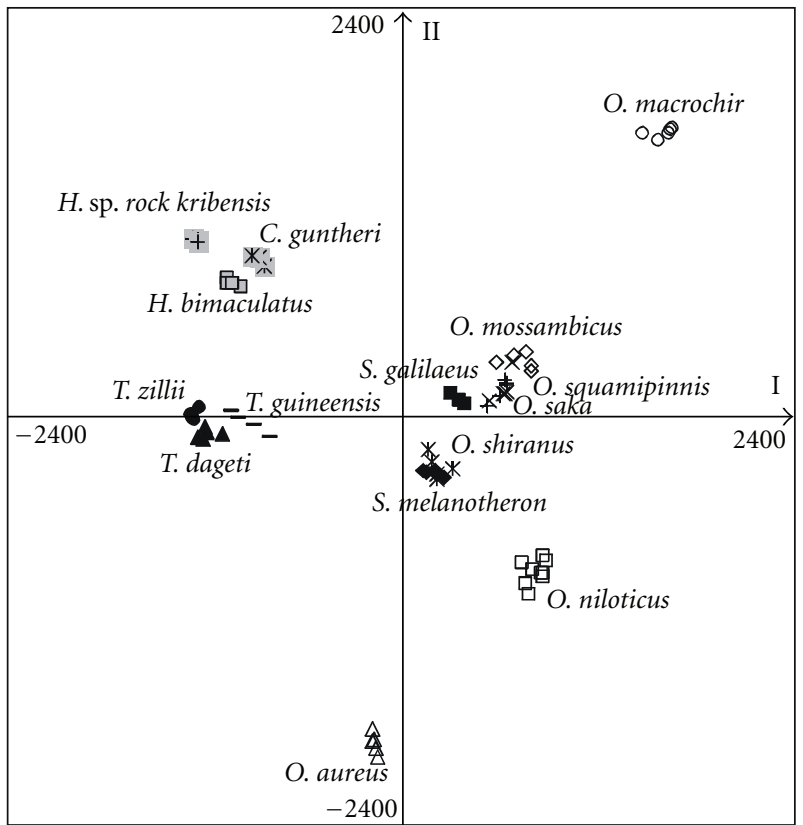

(a)

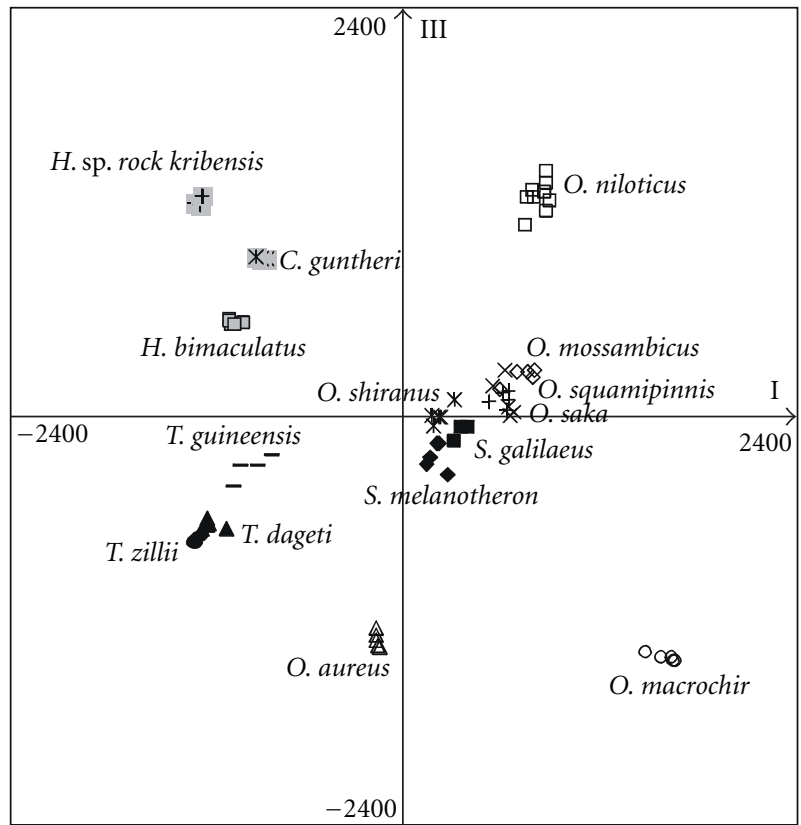

(b)

FIGURE 1: Clustering of the 15 study species based on multilocus diversity: correspondence analysis based on the individual genotypes over the 29 microsatellites loci successfully amplified and performed on the barycentre of the species: (a) factorial plane F1-F2 and (b) factorial planes F1-F3.

\section{Conclusion}

This study provides a quantitative estimate of the transferability of $O$. niloticus-derived microsatellites markers across 5 divergent African cichlid tribes, from the highly studied Haplochromines group to less studied tribes as Oreochromines, Boreotilapiines, Chromidotilapiines, and Hemichromines. The high rate of cross-species amplification and polymorphism highlights the usefulness of microsatellites markers for comparative genetic studies within Oreochromines and other African cichlids tribes, including stock/species identification, comparative genome mapping, candidate genes, or hybridisation surveys. Despite the fast growing opportunities to produce large-scale genomic data in nonmodel organisms, we believe that highly polymorphic, locus-specific markers such as microsatellites will continue to be useful for a wide range of genetic analyses in African cichlids.

\section{Acknowledgments}

The authors would like to thank Stéphane Mauger and René Guyomard for laboratory assistance; Frederic Clota, Martial Derivaz, Philippe Morisens, and Jérome Lazard for their support in the scientific program of inter-generic hybridisation of tilapias, as well as the anonymous referee and the 
editor, Kristina M. Sefc, for their valuable comments on the manuscript. This study was supported by grants from the CIRAD and INRA (France).

\section{References}

[1] T. D. Kocher, "Adaptive evolution and explosive speciation: the cichlid fish model," Nature Reviews Genetics, vol. 5, no. 4, pp. 288-298, 2004.

[2] I. Kornfield and P. F. Smith, "African cichlid fishes: model systems for evolutionary biology," Annual Review of Ecology and Systematics, vol. 31, pp. 163-196, 2000.

[3] O. Seehausen, "African cichlid fish: a model system in adaptive radiation research," Proceedings of the Royal Society B, vol. 273, no. 1597, pp. 1987-1998, 2006.

[4] G. W. Barlow, Cichlid Fishes: Nature's Grand Experiment in Evolution, Perseus Books, Cambridge, UK, 2000.

[5] H. A. Hofmann, "Functional genomics of neural and behavioral plasticity," Journal of Neurobiology, vol. 54, no. 1, pp. 272282, 2003.

[6] A. E. Eknath and G. Hulata, "Use and exchange of genetic resources of Nile tilapia (Oreochromis niloticus)," Reviews in Aquaculture, vol. 1, no. 3-4, pp. 197-213, 2009.

[7] H. Josupeit, World Market of Tilapia. Globefish Research Programme, FAO, Rome, Italy, 2005.

[8] R. S. V. Pullin, "Cichlids in aquaculture," in Cichlid Fishes: Behaviour, Ecology and Evolution, M. Keenleyside, Ed., pp. 280-300, Chapman \& Hall, London, UK, 1991.

[9] O. L. F. Weyl, A. J. Ribbink, and D. Tweddlel, "Lake Malawi: fishes, fisheries, biodiversity, health and habitat," Aquatic Ecosystem Health and Management, vol. 13, no. 3, pp. 241-254, 2010.

[10] F. Witte and W. L. T. van Densen, Fish Stocks and Fisheries; A Handbook for Field Observations, Samara House, Cardigan, UK, 1995.

[11] T. D. Kocher, "Status of genomic resources in tilapia (Oreochromis spp.)," in Proceedings of the Plant \& Animal Genome Conference, San Diego, Calif, USA, January 2001.

[12] T. D. Kocher, "Genome sequence of a cichlid fish: the Nile Tilapia (Oreochromis niloticus)," Proposal to the JGI Community Sequencing Program by he Cichlid Genome Consortium, 2005.

[13] W. J. Lee and T. D. Kocher, "Microsatellite DNA markers for genetic mapping in Oreochromis niloticus," Journal of Fish Biology, vol. 49, no. 1, pp. 169-171, 1996.

[14] T. D. Kocher, W. J. Lee, H. Sobolewska, D. Penman, and B. McAndrew, "A genetic linkage map of a cichlid fish, the tilapia (Oreochromis niloticus)," Genetics, vol. 148, no. 3, pp. 12251232, 1998.

[15] A. Estoup and B. Angers, "Microsatellites and minisatellites for molecular ecology: theoretical and empirical considerations," in Advances in Molecular Ecology, G. R. Carvalho, Ed., pp. 5579, IOS Press \& Ohmsha, 1998.

[16] P. Jarne and P. J. L. Lagoda, "Microsatellites, from molecules to populations and back," Trends in Ecology and Evolution, vol. 11, no. 10, pp. 424-429, 1996.

[17] J. A. DeWoody and J. C. Avise, "Microsatellite variation in marine, freshwater and anadromous fishes compared with other animals," Journal of Fish Biology, vol. 56, no. 3, pp. 461473, 2000.

[18] C. Rico, I. Rico, and G. Hewitt, " 470 million years of conservation of microsatellite loci among fish species," Proceedings of the Royal Society B, vol. 263, no. 1370, pp. 549-557, 1996.
[19] R. Zardoya, D. M. Vollmer, C. Craddock, J. T. Streelman, S. Karl, and A. Meyer, "Evolutionary conservation of microsatellite flanking regions and their use in resolving the phylogeny of cichlid fishes (Pisces: Perciformes)," Proceedings of the Royal Society B, vol. 263, no. 1376, pp. 1589-1598, 1996.

[20] C. R. Primmer, A. P. Moller, and H. Ellegren, "A wide-range survey of cross-species microsatellite amplification in birds," Molecular Ecology, vol. 5, no. 3, pp. 365-378, 1996.

[21] B. Y. Lee, W. J. Lee, J. T. Streelman et al., "A second-generation genetic linkage map of tilapia (Oreochromis spp.)," Genetics, vol. 170, no. 1, pp. 237-244, 2005.

[22] B. Y. Lee, G. Hulata, and T. D. Kocher, "Two unlinked loci controlling the sex of blue tilapia (Oreochromis aureus)," Heredity, vol. 92, no. 6, pp. 543-549, 2004.

[23] B. Y. Lee, D. J. Penman, and T. D. Kocher, "Identification of a sex-determining region in Nile tilapia (Oreochromis niloticus) using bulked segregant analysis," Animal Genetics, vol. 34, no. 5, pp. 379-383, 2003.

[24] J. T. Streelman and T. D. Kocher, "Microsatellite variation associated with prolactin expression and growth of saltchallenged tilapia," Physiological Genomics, vol. 2002, no. 9, pp. $1-4,2002$.

[25] K. A. Kellogg, J. A. Markert, J. R. Stauffer, and T. D. Kocher, "Microsatellite variation demonstrates multiple paternity in lekking cichlid fishes from Lake Malawi, Africa," Proceedings of the Royal Society B, vol. 260, no. 1357, pp. 79-84, 1995.

[26] M. J. H. Van Oppen, C. Rico, J. C. Deutsch, G. F. Turner, and G. M. Hewitt, "Isolation and characterization of microsatellite loci in the cichlid fish Pseudotropheus zebra," Molecular Ecology, vol. 6, no. 4, pp. 387-388, 1997.

[27] L. Wu, L. Kaufman, and P. A. Fuerst, "Isolation of microsatellite markers in Astatoreochromis alluaudi and their crossspecies amplifications in other African cichlids," Molecular Ecology, vol. 8, no. 5, pp. 895-897, 1999.

[28] M. I. Taylor, F. Meardon, G. Turner, O. Seehausen, H. D. J. Mrosso, and C. Rico, "Characterization of tetranucleotide microsatellite loci in a Lake Victorian, haplochromine cichlid fish: a Pundamilia pundamilia $x$ Pundamilia nyererei hybrid," Molecular Ecology Notes, vol. 2, no. 4, pp. 443-445, 2002.

[29] R. C. Albertson, J. T. Streelman, and T. D. Kocher, "Directional selection has shaped the oral jaws of Lake Malawi cichlid fishes," Proceedings of the National Academy of Sciences of the United States of America, vol. 100, no. 9, pp. 5252-5257, 2003.

[30] E. Crispo, C. Hagen, T. Glenn, G. Geneau, and L. J. Chapman, "Isolation and characterization of tetranucleotide microsatellite markers in a mouth-brooding haplochromine cichlid fish (Pseudocrenilabrus multicolor victoriae) from Uganda," Molecular Ecology Notes, vol. 7, no. 6, pp. 1293-1295, 2007.

[31] K. Maeda, H. Takeshima, S. Mizoiri, N. Okada, M. Nishida, and $\mathrm{H}$. Tachida, "Isolation and characterization of microsatellite loci in the cichlid fish in Lake Victoria, Haplochromis chilotes," Molecular Ecology Resources, vol. 8, no. 2, pp. 428430, 2008 .

[32] M. Sanetra, F. Henning, S. Fukamachi, and A. Meyer, "A microsatellite-based genetic linkage map of the cichlid fish, Astatotilapia burtoni (Teleostei): a comparison of genomic architectures among rapidly speciating cichlids," Genetics, vol. 182, no. 1, pp. 387-397, 2009.

[33] J. A. Markert, R. C. Schelly, and M. L. Stiassny, "Genetic isolation and morphological divergence mediated by high-energy rapids in two cichlid genera from the lower Congo rapids," BMC Evolutionary Biology, vol. 10, no. 1, article 149, 2010.

[34] D. Neumann, M. L. J. Stiassny, and U. K. Schliewen, "Two new sympatric Sarotherodon species (Pisces: Cichlidae) 
endemic to Lake Ejagham, Cameroon, west-central Africa, with comments on the Sarotherodon galilaeus species complex," Zootaxa, no. 2765, pp. 1-20, 2011.

[35] M. L. J. Stiassny and U. K. Schliewen, "Congochromis, a new cichlid genus (Teleostei: Cichlidae) from Central Africa, with the description of a new species from the upper Congo River, democratic Republic of Congo," American Museum Novitates, no. 3576, pp. 1-14, 2007.

[36] X. Rognon and R. Guyomard, "Large extent of mitochondrial DNA transfer from Oreochromis aureus to O. niloticus in West Africa," Molecular Ecology, vol. 12, no. 2, pp. 435-445, 2003.

[37] R. S. V. Pullin, Ressources Génétiques en Tilapias pour L'aquaculture, ICLARM, Manila, Philippines, 1988.

[38] E. Trewavas, Tilapiine Fishes of the Genera Sarotherodon, Oreochromis and Danakilia, British Museum Natural History, London, UK, 1983.

[39] S. Nagl, H. Tichy, W. E. Mayer, I. E. Samonte, B. J. McAndrew, and J. Klein, "Classification and phylogenetic relationships of African tilapiine fishes inferred from mitochondrial DNA sequences," Molecular Phylogenetics and Evolution, vol. 20, no. 3, pp. 361-374, 2001.

[40] V. Klett and A. Meyer, "What, if anything, is a Tilapia? Mitochondrial ND2 phylogeny of tilapiines and the evolution of parental care systems in the African cichlid fishes," Molecular Biology and Evolution, vol. 19, no. 6, pp. 865-883, 2002.

[41] J. Schwarzer, B. Misof, D. Tautz, and U. K. Schliewen, "The root of the East African cichlid radiations," BMC Evolutionary Biology, vol. 9, no. 1, article 186, 2009.

[42] G. W. Wohlfarth, "The unexploited potential of tilapia hybrids in aquaculture," Aquaculture \& Fisheries Management, vol. 25, no. 8, pp. 781-788, 1994.

[43] M. J. Genner, O. Seehausen, D. H. Lunt et al., "Age of cichlids: new dates for ancient lake fish radiations," Molecular Biology and Evolution, vol. 24, no. 5, pp. 1269-1282, 2007.

[44] "Marqueurs microsatellites: isolement à l'aide de sondes nonradioactives, caractérisation et mise au point," http://www. agroparistech.fr/svs/genere/microsat/microsat.htm.

[45] A. Estoup, K. Gharbi, M. SanCristobal, C. Chevalet, P. Haffray, and R. Guyomard, "Parentage assignment using microsatellites in turbot (Scophthalmus maximus) and rainbow trout (Oncorhynchus mykiss) hatchery populations," Canadian Journal of Fisheries and Aquatic Sciences, vol. 55, no. 3, pp. 715-725, 1998.

[46] K. Belkhir, P. Borsa, L. Chikhi, N. Raufaste, and F. Bonhomme, GENETIX 4.02, Logiciel Sous Windows pour la Génétique des Populations, Laboratoire Génome, Populations, Interactions, CNRS UMR 5000, Université de Montpellier II, Montpellier, France, 2001. 

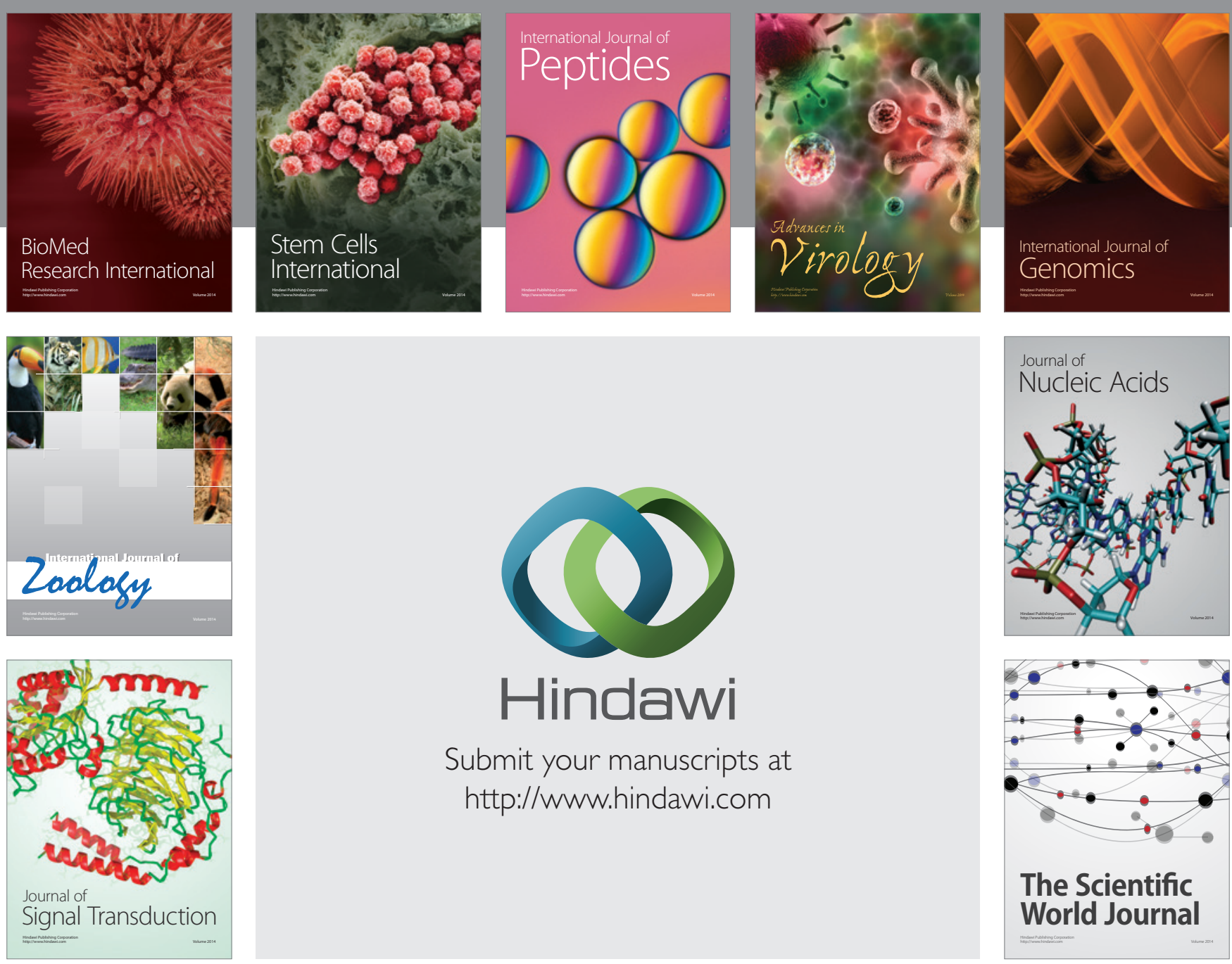

Submit your manuscripts at

http://www.hindawi.com
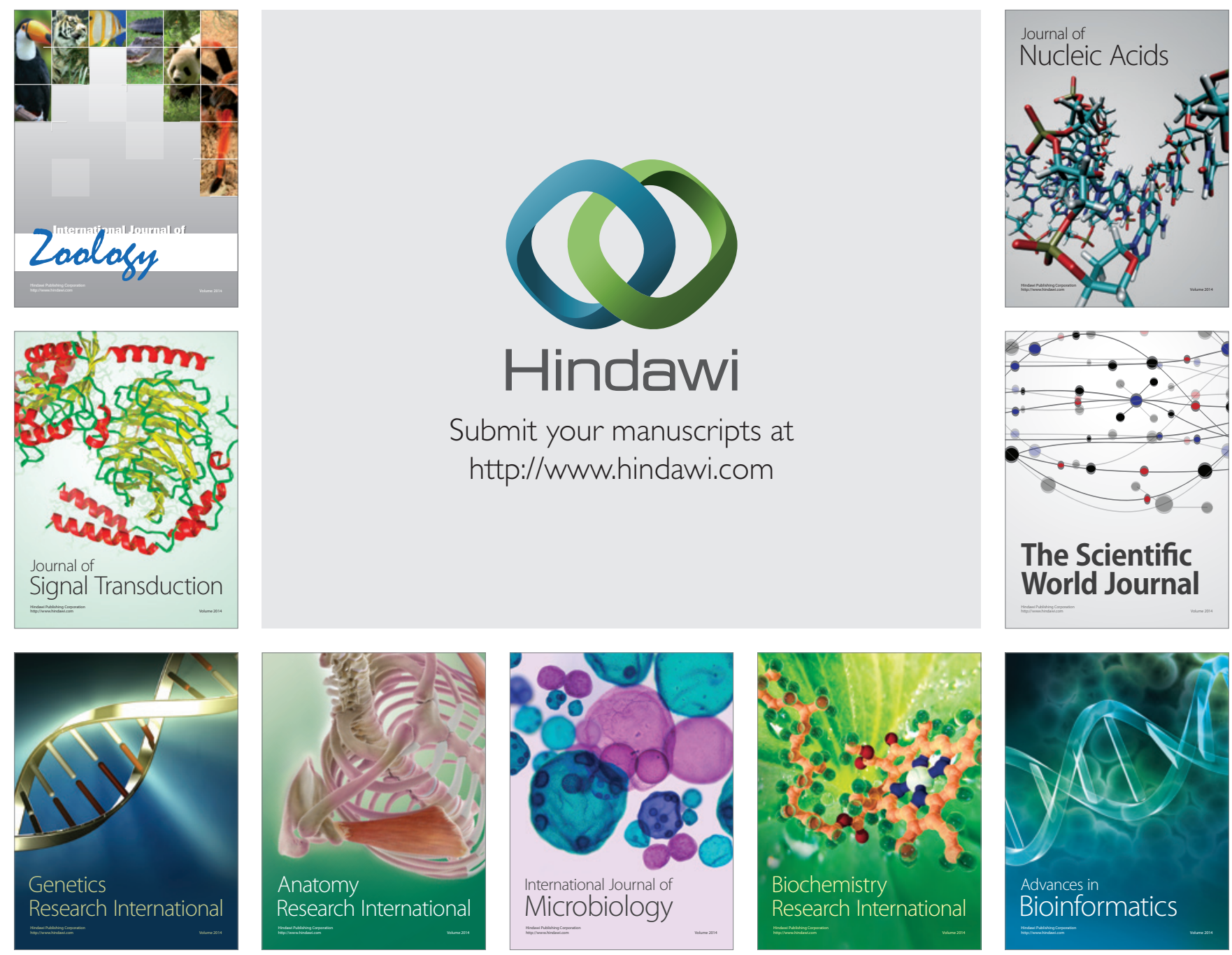

The Scientific World Journal
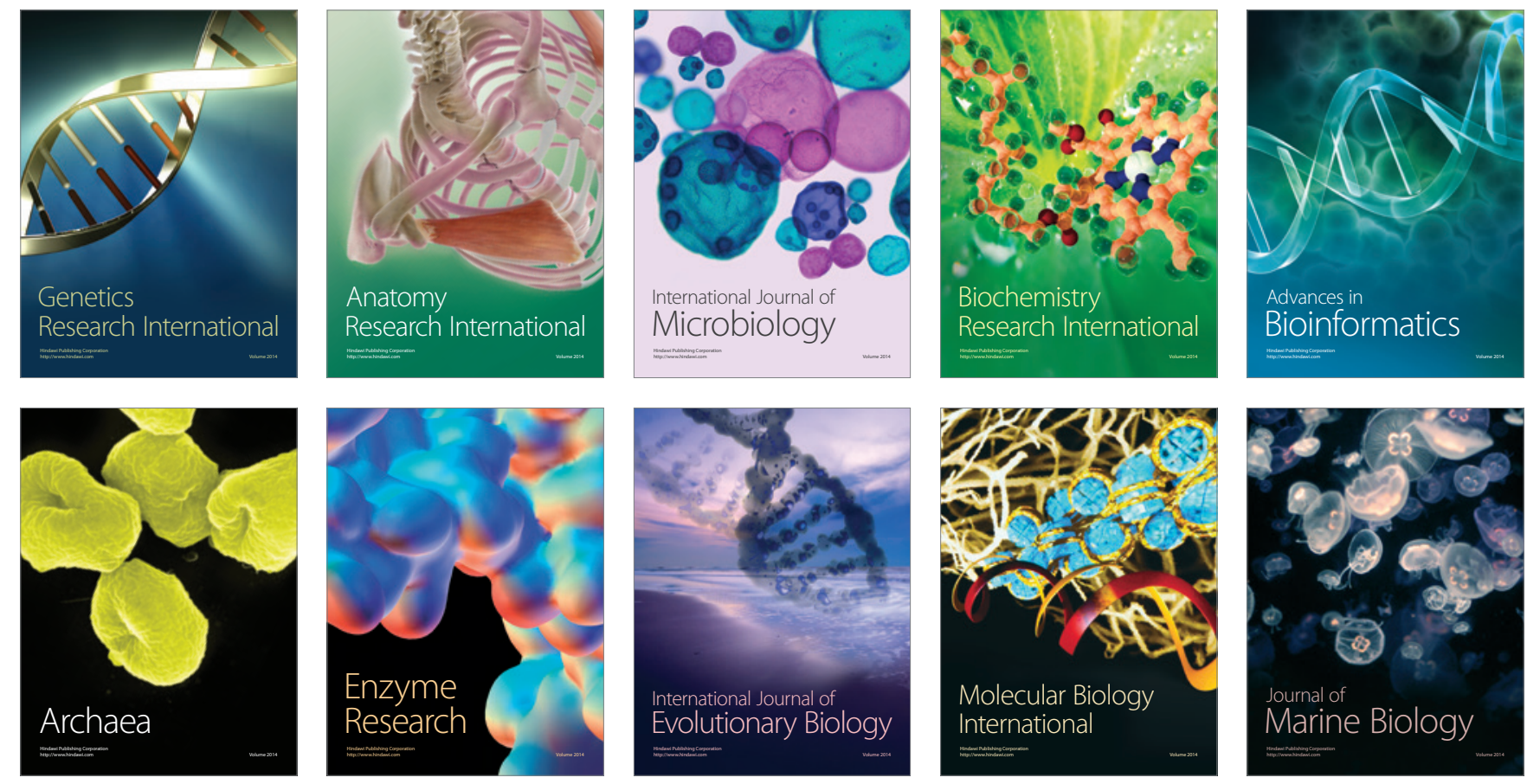